\title{
Association between suicide reporting in the media and suicide: systematic review and meta-analysis
}

\author{
OPEN ACCESS
}

Thomas Niederkrotenthaler associate professor ${ }^{12}$, Marlies Braun postgraduate researcher ${ }^{12}$, Jane Pirkis professor ${ }^{3}$, Benedikt Till associate professor ${ }^{12}$, Steven Stack professor ${ }^{4}$, Mark Sinyor associate professor $^{56}$, Ulrich S Tran senior lecturer ${ }^{2}{ }^{7}$, Martin Voracek professor ${ }^{2}{ }^{7}$, Qijin Cheng assistant professor $^{8}$, Florian Arendt assistant professor ${ }^{2}{ }^{9}$, Sebastian Scherr assistant professor ${ }^{10}$, Paul S F Yip professor ${ }^{11}$, Matthew J Spittal associate professor ${ }^{3}$

\footnotetext{
${ }^{1}$ Unit Suicide Research and Mental Health Promotion, Department of Social and Preventive Medicine, Centre for Public Health, Medical University of Vienna, Kinderspitalgasse 15, A-1090 Vienna, Austria; ${ }^{2}$ Wiener Werkstaette for Suicide Research, Vienna, Austria; ${ }^{3}$ Centre for Mental Health, Melbourne School of Population and Global Health, University of Melbourne, Melbourne, VIC, Australia; ${ }^{4}$ Department of Criminology and Department of Psychiatry, Wayne State University, Detroit, MI, USA; ${ }^{5}$ Department of Psychiatry, Sunnybrook Health Sciences Centre, Toronto, ON, Canada; ${ }^{6}$ Department of Psychiatry, University of Toronto, Toronto, ON, Canada; ${ }^{7}$ Department of Basic Psychological Research and Research Methods, School of Psychology, University of Vienna, Vienna, Austria; ${ }^{8}$ Department of Social Work, Chinese University of Hong Kong, Hong Kong, China; ${ }^{9}$ Department of Communication, University of Vienna, Vienna, Austria; ${ }^{10}$ School for Mass Communication Research, KU Leuven, Leuven, Belgium; ${ }^{11}$ Centre for Suicide Research and Prevention, and Department of Social Work and Social Administration, University of Hong Kong, Hong Kong, China
}

\begin{abstract}
Abstract

Objective - To examine the association between reporting on suicides, especially deaths of celebrities by suicide, and subsequent suicides in the general population.

Design - Systematic review and meta-analysis.

Data sources - PubMed/Medline, Psychlnfo, Scopus, Web of Science, Embase, and Google Scholar, searched up to September 2019.

Review methods - Studies were included if they compared at least one time point before and one time point after media reports on suicide; follow-up was two months or less; the outcome was death by suicide; and the media reports were about non-fictional suicides. Data from studies adopting an interrupted time series design, or single or multiple arm before and after comparisons, were reviewed.

Results -31 studies were identified and analysed, and 20 studies at moderate risk of bias were included in the main analyses. The risk of suicide increased by $13 \%$ in the period after the media reported a death of a celebrity by suicide (rate ratio $1.13,95 \%$ confidence interval 1.08 to $1.18 ; 14$ studies; median follow-up 28 days, range 7-60 days). When the suicide method used by the celebrity was reported, there was an associated $30 \%$ increase in deaths by the same method (rate ratio 1.30 , $95 \%$ confidence interval 1.18 to $1.44 ; 11$ studies; median follow-up 28 days, range 14-60 days). For general reporting of suicide, the rate ratio was 1.002 (0.997 to 1.008 ; five studies; median follow-up 1 day, range
\end{abstract}

1-8 days) for a one article increase in the number of reports on suicide. Heterogeneity was large and partially explained by celebrity and methodological factors. Enhanced funnel plots suggested some publication bias in the literature.

Conclusions - Reporting of deaths of celebrities by suicide appears to have made a meaningful impact on total suicides in the general population. The effect was larger for increases by the same method as used by the celebrity. General reporting of suicide did not appear to be associated with suicide although associations for certain types of reporting cannot be excluded. The best available intervention at the population level to deal with the harmful effects of media reports is guidelines for responsible reporting. These guidelines should be more widely implemented and promoted, especially when reporting on deaths of celebrities by suicide.

Systematic review registration - PROSPERO CRD42019086559.

\section{Introduction}

News reporting of suicide has increased substantially in recent decades. ${ }^{1-4}$ A number of studies have shown that media reports of suicide are associated with increased numbers of suicides. ${ }^{5-10}$ Media related imitation of suicide has been dubbed the Werther effect, based on a reported spike in suicides in young men in Germany and across Europe after the publication of Goethe's The sorrows of young Werther in 1774, depicting the circumstances leading to the suicide of the male protagonist 
Werther. ${ }^{11}$ More than 150 studies have investigated the effects of suicide related to media reports. ${ }^{10}$ Most have used before and after comparisons or time series designs, testing whether media reporting was associated with subsequent changes in suicides at an aggregate level across a region of exposure. The Werther effect is discussed mostly in relation to non-fictional news stories, ${ }^{8}$ particularly stories about deaths of celebrities by suicide, ${ }^{6}$ and stories with a dramatic or romanticised depiction of suicide, or featuring an explicit and detailed description of a suicide method. ${ }^{12-14}$

In acknowledgment of the Werther effect, mental health and suicide prevention organisations worldwide, including the World Health Organization, have developed guidelines for responsible reporting of suicide by the media with a specific focus on news and information media. ${ }^{15} 16$ These guidelines are now a standard component of many national and regional suicide prevention strategies. ${ }^{16}$ Typically included in the guidelines are specific suggestions about ways to minimise harm (eg, by avoiding glorification of suicide, discussions of specific suicide methods, and repeated reporting about the same suicide). The guidelines also recommend including information on the role of treatable mental illness, where and how to seek help for suicidal thoughts, and a message of hope that suicide is preventable. But specific information on individual deaths by suicide continues to be published; the suicide of the actor Robin Williams is an example of the guidelines not being fully followed. ${ }^{1718}$

Controversies around suicide and the media remain, despite a global focus on avoiding the Werther effect and compelling associations in the literature. Research shows that not all media coverage of suicide is associated with subsequent increases in suicides, resulting in a debate lasting decades on the impact of media reporting of suicide on subsequent suicides. ${ }^{9}{ }^{101314} 19$ In several countries that have implemented media guidelines, journalists and media professionals have pushed back, arguing that the body of evidence is not compelling enough to warrant changes to the way suicide is reported. ${ }^{1020}$

Meta-analyses can better quantify the combined evidence of a Werther effect across published studies, but these studies are scarce. One meta-analysis of 10 studies examined media reporting on deaths of celebrities by suicide and found an average increase of 2.6 suicides per million people $(95 \%$ confidence interval 0.9 to 4.3 ) in the month after the reports of death. ${ }^{6}$ In the largest meta-analysis so far, Stack ${ }^{9}$ combined findings from 55 studies examining non-fictional reports of suicide as a predictor of suicide, and found that only $36 \%$ identified an apparent Werther effect. This meta-analysis did not, however, define clear inclusion and exclusion criteria; consider the quality of the studies; account for potential duplication of results; and, crucially, involve the abstraction of quantitative data on suicides (as is normally the case). The outcome of the meta-analysis was a binary variable of increase versus no increase in suicides.

Media coverage of celebrity deaths by suicide is a small proportion of all suicide reporting ${ }^{8-101314}$ and the guidelines make recommendations about all forms of reporting of suicide. ${ }^{16}$ Meta-analyses on the effects of general reporting of suicide (that is, any reporting related to suicide) are lacking. General reporting of suicide might involve deaths of celebrities or other individuals, or might include more general discussions on the topic of suicide. These studies typically use broad search terms to identify media reports (eg, suicide or various suicide methods).

The aim of this systematic review and meta-analysis was to examine and quantify the findings from the literature on the
Werther effect. We aimed to evaluate the effects of three types of media reporting on suicide on the subsequent incidence of suicide. The primary objective was to summarise the evidence on the association of media reporting of deaths of celebrities by suicide on total suicides over a short period of time (up to two months). The secondary objectives were to summarise the association of media reporting of information about the specific methods used by the celebrities on suicides by the same method, and the association of general reporting of suicide on the total number of suicides. We hypothesised that reporting of the deaths of celebrities by suicide would be associated with an increased incidence of suicide in the general population, and that increases by the same method would be strongest. We did not have a clear hypothesis for general reporting of suicide because of the variety of content, some of which might be harmful and some protective. ${ }^{1314}$ For our meta-analysis, we use the term "intervention" to refer to media reporting of suicide. The study was conducted according to the meta-analyses of observational studies in epidemiology (MOOSE) guidelines.

\section{Methods}

\section{Search strategy}

We defined news and information media as all non-fictional accounts of suicide on TV, in print, in online news, or in educational non-fiction media (eg, non-fiction books or films). Studies on the effects of searching for suicide related information online (eg, Google searches) were not eligible because these studies do not distinguish between positive (eg, for help services) and negative (eg, pro-suicide websites) searching. ${ }^{21}$ We searched PubMed/Medline, Embase, PsycInfo, Scopus, Web of Science, and Google Scholar for relevant studies from their inception to September 2019. These databases show modest to strong overlap in coverage. ${ }^{22}$ Google Scholar was used specifically to identify grey literature. ${ }^{23}$ We used the search terms suicide (suicid*) AND imitation (Werther; Papageno; copycat; imitat*; contagio*; suggesti*); AND media (media; newspaper*; print; press; radio*; televis*; film*; book*; documentar*; internet; cyber*; web*).

The titles and abstracts of the retrieved articles were screened for relevance, and the full text versions of studies that might meet the inclusion criteria were reviewed. The reference lists of the full text articles were also screened for relevant studies, and a cited reference search was conducted for all relevant primary articles with Google Scholar. English and non-English language articles were included. Non-English articles often had English abstracts, and we used Google Translate and consulted with fluent language speakers to assess the inclusion criteria and extract the data.

\section{Study selection}

Studies were eligible for inclusion if they used a before-and-after design, compared single or multiple times before-and-after media reports related to suicide, or an interrupted times series design; if they used death by suicide as the outcome variable; and if they reported non-fictional media stories (that is, stories in news and information media).

\section{Exclusion criteria}

We excluded studies that did not have original data. We also excluded studies that examined associations in subgroups of the population because the findings might not be representative of the total population. For our analysis of media reporting on the method of suicide, we excluded studies reporting on an 
emerging new suicide method if the incidence of the respective suicide method at baseline (that is, before onset of media reporting) was low $(<5 \%)$. These studies also typically measured possible effects over a longer than usual period of time. We excluded studies that provided only associations for a follow-up period of more than two months, because this is beyond the typical time frame for studying imitation effects, and might be based on mechanisms that are different from imitation. ${ }^{24}$ Also excluded were studies with data before the second world war; those with media interventions that were not about suicide; those which applied non-eligible designs; those that were at critical risk of bias; or those that duplicated data from another study.

If studies had duplicated data (data on the same celebrities in the same setting reported in more than one study), we included one study. We selected this using a hierarchical approach based on: (1) the lowest risk of bias; (2) covering the longest period of time or the largest number of celebrities; and (3) the most recent. The 31 studies selected were included in the qualitative and quantitative synthesis (supplementary appendix).

\section{Data extraction}

We extracted these data from the studies: study location; study period and length; length of the observation period after media reporting; unit of analysis at which outcome data were measured (eg, daily or weekly); how the media intervention was measured (eg, binary variable representing the presence or absence of reporting or a continuous variable representing the number of news stories); whether the study reported on deaths of celebrities by suicide or general reports of suicide; number of interventions (eg, number of media reports over time); type of media (print media $v$ other forms of media, such as television, online, or mixed media); any outcome reported related to the specific suicide method used in a reported suicide (exclusively or in addition to total suicides); whether the analysis was adjusted or unadjusted for confounders (in addition to any adjustments for seasonal or long term time trends); which confounders were measured and adjusted for; type of estimate extracted (rate ratio or expected and observed suicides); study design (single arm before and after comparison, multiple arm before and after comparison, interrupted time series ${ }^{25-28}$; analysis technique; method to control for time trends; and source of the outcome data. In a single arm before-and-after comparison, suicides were observed in one group before and after the intervention. In a multiple arm before-and-after comparison, suicides were observed in multiple groups because there were multiple sites for one intervention or one site but multiple interventions occurring at different times. ${ }^{25}$

Additional information was obtained for studies of deaths of celebrities by suicide: number of celebrities; type of celebrity (eg, entertainer); and level of recognition of the celebrity (local, international). For level of recognition, we used information from the study and online sources (eg, Wikipedia). Local celebrities were famous in one country or region (eg, a local politician) and international celebrities were known in a western or global context or were described in the original publication as international. A mixed code was used for celebrities with different levels of recognition. For studies looking at increases in the incidence of suicide by the same method as reported in the media, we recorded the suicide method.

We obtained rate ratios and standard errors from each study by one of the following methods:

- Extracting directly a rate ratio and either a standard error, 95\% confidence interval, $t$ value, or other estimate to calculate a standard error
- Using the number of expected and observed suicides to calculate rate ratios and standard errors

- Extracting the observed number of suicides in the before and after intervention periods (along with the corresponding times) and calculated rate ratios and standard errors

- Obtaining a coefficient and standard error from a linear regression model that was converted to a rate ratio with the study's population at the mid-point

- The authors of the original study providing us with rate ratios and standard errors.

For each study, we recorded how the estimate was derived (obtained directly from the study, combined estimates using meta-analysis, or reanalysis of the data by the authors).

We aimed for one quantitative outcome, but two studies (table S1) reported multiple quantitative estimates because the results were presented separately for different news sources. Hence we combined these into one estimate using random effects meta-analysis (see below).

The search strategy was performed by two of the authors (TN and MB). Decisions on excluding studies after full text review were made by TN and separately by MJS. Discrepancies were discussed and resolved. Quantitative data were abstracted by MJS and discussed with TN. Metadata of studies were obtained by TN and MB initially, and separately by MJS. Discrepancies were discussed and resolved among the team.

\section{Risk of bias}

Risk of bias was assessed for each study based on the Robins-I tool. ${ }^{29}$ This tool was originally designed for non-randomised cohort studies, and does not directly apply to our study designs. The general concept, however, is applicable to interrupted time series designs, ${ }^{30}$ and the authors of Robins-I have published on issues that will be looked at in a future version for studies of interrupted time series. ${ }^{31}$ We developed a specific adaption for this study with six domains of bias: bias as a result of confounding issues; bias in classification of interventions; bias because of preparatory phases; bias because of missing data; bias in measurement of the outcome; and bias in selection of reported results.

Studies were considered at low risk of bias if all domains were coded as low risk; at moderate risk if at least one domain was coded moderate but none as serious; at serious risk if at least one domain was assessed as serious but none as critical; and at critical risk if any domain was coded as critical. Like an earlier study that applied the Robins-I tool to natural experiments, ${ }^{30}$ we found that the first domain, risk of bias as a result of confounding, generally determined the overall risk of bias. This domain comprised coding for subdomains if the number of pre-intervention times was sufficient to allow characterisation of the series; appropriate analysis techniques were used to account for time trends and time patterns; seasonality was accounted for; and possible confounders were measured and controlled for. Risk of bias because of selective reporting was also relevant for some studies. We assessed if the outcome measurement and analyses were clearly defined and consistent in the methods and results sections of the studies, and if there was some risk of selective reporting from multiple analysis methods, multiple follow-up times, or multiple subgroups. The full quality assessment plan is in the supplementary appendix.

As recommended in the Robins-I tool, studies with up to moderate risk were included in the primary and secondary analyses, and studies at serious risk were included in sensitivity analyses only. Studies at critical risk of bias were excluded. 
Assessments of the risk of bias were based only on the data we abstracted. If the authors provided a reanalysis of their data, for example, only the reanalysis was assessed for risk of bias, not the original study. Similarly, if a study reported total suicides as a side outcome, only the components relevant to the abstracted data (total suicides) were assessed. Our quality ratings, therefore, do not always apply to the original studies. Risk of bias was assessed independently by TN and MJS, and discrepancies were discussed and resolved.

\section{Quantitative data synthesis}

We described the studies using descriptive statistics. For our primary analysis, we estimated the pooled rate ratio for the effect of media reporting on deaths of celebrities by suicide on total suicides. We also conducted two secondary analyses. In the first (secondary analysis A), we estimated the pooled rate ratio for reporting about the method used in a suicide by a celebrity on suicide by the same method. In the second (secondary analysis B), we estimated the pooled rate ratio for general reporting of suicide on total suicides. The primary and two secondary analyses were restricted to studies at moderate risk of bias. In sensitivity analyses, we repeated these analyses adding studies at serious risk of bias.

All pooled rate ratios were estimated with a random effects model, with standard errors calculated by the Knapp-Hartung method.$^{32}$ Heterogeneity of effect sizes was assessed with the $\mathrm{I}^{2}$ statistic and Cochran's Q test. For I $\mathrm{I}^{2}$, values around $25 \%$ indicated low heterogeneity, around 50\% moderate heterogeneity, and around $75 \%$ high heterogeneity. ${ }^{33}$ Publication bias was assessed visually by contour enhanced funnel plots ${ }^{34}$ and quantitatively with Egger's regression test for asymmetry. ${ }^{35}$

\section{Sources of heterogeneity}

Meta-regression was used to identify the factors that might contribute to heterogeneity. We conducted univariate meta-regressions for each variable and combined significant variables $(\mathrm{P}<0.05)$ into a multivariate model. The meta-regressions were estimated with a random effects model with standard errors calculated by the Knapp-Hartung method. We combined the coefficients algebraically (that is, a linear combination of coefficients presented on the exponential scale) so that we could show rate ratios and $95 \%$ confidence intervals in each category of a variable. For the studies in the primary analysis, we examined the period published (up to 2005 , 2006-10, 2011-15, 2016 or later), follow-up time ( $\leq 14$ days, $\geq 15$ days) location (Asia, Europe, North America-Australia), design (multiple arm before-and-after comparison, interrupted time series analysis), length (per 1000 days), period of analysis (day, week, month), adjustment for confounders (no, yes), celebrity recognition (local, international, mixed), celebrity type (entertainer, other), and number of celebrities $(1, \geq 2)$. We used similar variables for the studies in secondary analysis A, along with a variable on the method of suicide reported (hanging $v$ other methods) but combined several categories where only one study was available for analysis. We did not conduct a meta-regression for studies in secondary analysis B because heterogeneity was low. All analyses were conducted in Stata 16.0. This study was registered with PROSPERO (https://www. crd.york.ac.uk/PROSPERO/, registration No CRD42019086559, 18 January 2019).

\section{Patient and public involvement}

There were no funds or time allocated for patient and public involvement so we were unable to involve patients. We have invited patients to help us develop our dissemination strategy.

\section{Results \\ Study characteristics}

We retrieved 8823 references and 1496 remained after removal of duplicates (fig 1). After screening the titles and abstracts, the full texts of 143 studies were assessed and 112 were excluded: 26 because suicide was not an outcome; 30 because of strong data duplication with other studies; 17 because the intervention (media story) was not about suicide; 19 because of reports on emerging suicide methods; five because suicide was analysed only in a population subgroup; and five had data from before the end of the second world war. Also excluded were: two case studies; two studies measuring the outcome for longer than the maximum follow-up; one study about a fictional intervention; and two studies with annual outcome data. After quality assessment, three studies were excluded because of a critical risk of bias. The remaining 31 studies were included in our review: 23 were from database searches, three from Google Scholar, and five from cross reference searches.

Study characteristics are summarised in table 1 and table 2 (and table S1). The 31 studies were published between 1974 and 2019 and examined the period 1947 to 2016 . Nineteen studies examined the total number of suicides as the outcome and two examined increases in suicides by the same method reported in the media; 10 studies reported both. Twenty two studies examined media reporting of deaths of celebrities by suicide and nine studies evaluated general reporting of suicide. Studies were from Asia (Taiwan, Hong Kong, South Korea, and Japan), Europe (Austria, Germany, Hungary, the Netherlands, Slovenia, France, and Israel), North America (United States and Canada), and Australia. Most studies $(\mathrm{n}=20)$ used an interrupted time series design, 10 a multiple arm before-and-after design, and one a single arm before-and-after design. Seven studies had follow-up of 1-7 days, eight had 8-14 days, 12 had 15-30 days, and four had 31-60 days. The median follow-up time was 21 days (range 1-60 days).

\section{Quality assessment}

We classified 24 studies as being at moderate risk of bias because of confounding issues and seven at serious risk of bias. We judged 22 studies as being at low risk of bias because of classification of interventions, six at moderate risk, and three at serious risk. All 31 studies were at low risk of bias because of preparatory phases. Twenty eight studies were at low risk of bias because of missing data, two were at moderate risk, and for one the risk was unknown. Thirty studies were at low risk of bias because of measurement of the outcome, and one was at serious risk. Twenty nine studies were judged to be at moderate risk of bias because of selection of reported results, and two were at serious risk. Overall, 20 studies were assessed as moderate risk and 11 as serious risk of bias (table S2).

\section{Quantitative data synthesis}

Figure 2, figure 3, and figure 4 show the forest plots for the primary and secondary analyses. For the primary analysis (fig 2), on the impact of media reporting of deaths of celebrities by suicide on total suicides, 14 studies met the inclusion criteria. The pooled rate ratio was 1.13 (95\% confidence interval 1.08 to $1.18, \mathrm{P}<0.001$ ) over a median follow-up of 28 days (range 
7-60 days). For the secondary analysis A (fig 3), on reporting of method of suicide of celebrities on suicides by the same method, 11 studies met the inclusion criteria. The pooled rate ratio was 1.30 (95\% confidence interval 1.18 to $1.44, \mathrm{P}<0.001$ ) over a median follow-up of 28 days (range 14-60 days). For the secondary analysis B (fig 4), on the impact of general reporting of suicide on total suicides, five studies met the inclusion criteria and the pooled rate ratio was 1.002 (95\% confidence interval 0.997 to $1.008, \mathrm{P}=0.25$ ) for a one article increase in the number of reports on suicide. The median follow-up was 1 day (range 1-8 days).

\section{Heterogeneity}

Estimates of heterogeneity were large and significant for the primary analysis $\left(\mathrm{I}^{2}=83.5 \%, \mathrm{P}<0.001\right)$ and the secondary analysis A $\left(\mathrm{I}^{2}=72.1 \%, \mathrm{P}<0.001\right)$ but not for the secondary analysis $\mathrm{B}$ $\left(\mathrm{I}^{2}=0.02 \%, \mathrm{P}=0.40\right)$. We therefore undertook meta-regressions for the first two sets of studies to identify possible sources of heterogeneity.

In univariate analyses of the 14 studies in the primary analysis, differences in the pooled rate ratios between subgroups were observed for three variables (table 3$)$ : publication date $(\mathrm{P}=0.04$, $\left.\mathrm{I}^{2}=29.1 \%\right)$, celebrity type $\left(\mathrm{P}=0.009, \mathrm{I}^{2}=47.9 \%\right)$, and number of celebrities under investigation $\left(\mathrm{P}=0.009, \mathrm{I}^{2}=47.0 \%\right)$. Weak evidence that reporting of deaths of celebrities by suicide was associated with suicides was found for studies published before 2005 (rate ratio $1.12,95 \%$ confidence interval 0.99 to 1.26 , two studies) but clear evidence of a positive association was found for the three other times (2006-10: 1.13, 1.04 to 1.23, three studies; 2011-15: 1.06, 1.02 to 1.10 , four studies; $\geq 2016$ : 1.16 , 1.11 to 1.22 , five studies). Suicides by entertainers showed a positive association between reporting and suicide (rate ratio $1.17,1.12$ to 1.23 , six studies) as did studies about other types of celebrities (1.08, 1.04 to 1.12, eight studies). Studies about one celebrity $(1.17,1.12$ to 1.23 , seven studies) and multiple celebrities (1.08, 1.04 to 1.12 , seven studies) showed positive associations between reporting of deaths of celebrities by suicide and suicide.

Because celebrity type and number of celebrities were collinear, we entered only publication date and number of celebrities in a multivariate meta-regression. We found no differences between subgroups in the pooled rate ratio for either variable (table S3) but the overall $\mathrm{I}^{2}$ for the model was lower, indicating low to moderate heterogeneity compared with the primary analysis $\left(I^{2}=34.6 \%\right)$. In the meta-regressions of the nine studies in the secondary analysis A, none of the factors was associated with the reporting of method of suicide on total suicides (table S4).

\section{Publication bias}

Figure 5 shows the contour enhanced funnel plots for the three analyses. For the primary analysis, the funnel plot was asymmetrical with more study specific rate ratios falling to the right of the pooled rate ratio line than the left. Few rate ratios were within the $\mathrm{P}$ value greater than $10 \%$ contours of statistical significance. Studies appeared to be missing from the region between the null value and the pooled rate ratio. Egger's regression test for funnel plot asymmetry was significant $(\mathrm{P}=0.01)$. The funnel plots for the two secondary analyses were symmetrical around the pooled rate ratio, and Egger's test was not significant for either analysis $(\mathrm{P}=0.23$ for secondary analysis $\mathrm{A}$ and $\mathrm{P}=0.13$ for secondary analysis $\mathrm{B}$ ).

\section{Sensitivity analyses}

We undertook sensitivity analyses that included studies at serious risk of bias (fig S1). For media reporting of deaths of celebrities by suicide on total suicides, 20 studies met the inclusion criteria. The pooled rate ratio was $1.10(95 \%$ confidence interval 1.06 to $1.14, \mathrm{P}<0.001, \mathrm{I}^{2}=93.4 \%$ ) over a median follow-up of 28 days (range 7-60 days). Investigation of heterogeneity failed to identify new factors that could account for differences between the studies. Heterogeneity remained large and persisted for all variables (table S5). Egger's regression test for funnel plot asymmetry (fig S2) was close to significance $(\mathrm{P}=0.06)$. For reporting of the suicide method used by a celebrity on suicide by the same method ( 12 eligible studies), the pooled rate ratio was 1.32 (95\% confidence interval 1.19 to 1.47 , $\mathrm{P}<0.001, \mathrm{I}^{2}=74.9 \%$ ) over a median follow-up of 28 days (range 14-60 days). We were unable to find sources of heterogeneity (table S6). Egger's test was not significant $(\mathrm{P}=0.10)$. For general reporting of suicide (nine studies, median follow-up 7 days, range 1-30 days), the pooled rate ratio was 1.002 (95\% confidence interval 0.999 to $1.005, \mathrm{P}=0.11, \mathrm{I}^{2}=0.02 \%$ ) for an increase of one article. Egger's test was not significant $(\mathrm{P}=0.60)$. Because three studies in the primary analysis were about the same celebrity (Robin Williams), we performed a final sensitivity analysis where we excluded two of the studies, retaining the study with the lowest risk of bias. ${ }^{36}$ The pooled rate ratio was 1.10 (95\% confidence interval 1.06 to 1.15 , $\mathrm{P}<0.001, \mathrm{I}^{2}=61.8 \%$ ) over a median follow-up of 28 days (range 7-60 days).

\section{Discussion \\ Main findings}

To our knowledge, this systematic review and meta-analysis is the most comprehensive to date of the effects of media reporting of suicide on subsequent suicides. The evidence indicates an increase in total suicides in the period after the reporting of a death of a celebrity by suicide. When the suicide method used by the celebrity was reported, evidence of a corresponding increase in the number of suicides by the same method was found. This effect appeared to be larger than for increases in total suicides, although suicides by a specific method typically only account for a limited proportion of all suicides. General reporting of suicide did not appear to be associated with increases in total suicides but the evidence was based on a small number of studies, mainly from the same region of the world. At least three mechanisms might explain the increases in the number of suicides associated with reporting of suicide: identification with the deceased person, which might occur more frequently when the reported suicides are about individuals with high social standing ${ }^{37} 38$; increased media reporting of suicide leading to normalisation of suicide as an acceptable way to cope with difficulties ${ }^{7}$; and information on suicide methods, which might influence the choice of suicide method by a vulnerable individual. ${ }^{38}$ Our findings support several of these mechanisms Firstly, reporting on deaths of celebrities by suicide appears to increase total suicides, suggesting that the phenomenon goes beyond the influence of knowing the suicide method used by the celebrity. Secondly, some evidence exists of stronger effects in studies focusing on suicide by entertainers, compared with other celebrities, consistent with their strong public identity, which has been previously described for entertainment celebrities in particular. ${ }^{39}$ Studies that focused on increases in suicide after one (rather than several) suicide by a celebrity often reported on entertainers, suggesting that these celebrities were well known and of interest to the public. Thirdly, the 
finding of a pronounced increase in suicide by the same method as that of a celebrity suggests that transfer of information about the method might be another relevant factor in the association. Media reporting on a suicide method increases the cognitive availability of this method, ${ }^{7}$ and individuals considering suicide might be more likely to subsequently select the method used by celebrities. The evidence suggests that suicide by hanging, for example, especially among men aged 45-64 years, increased after the suicide of Robin Williams by the same method. ${ }^{36}$

Support for the effect of media coverage of suicide also comes from individual level studies that typically used outcomes such as suicidal thoughts rather than suicidal behaviour. Harmful effects on mood, self-esteem, and suicidal thoughts, especially in those who have previously contemplated suicide, have been identified. ${ }^{40-42}$ Individuals with suicidal thoughts, particularly new thoughts and a suicide plan, have an increased risk of suicidal behaviour. ${ }^{43}$ The increases in total suicides, and greater increases in suicides by the same method reported in the media, as identified in our meta-analysis, suggest that media stories on deaths of celebrities by suicide might do both: increase suicidal thoughts and contribute to planning suicide with a specific method. Suicidal thoughts are a common occurrence. A recent survey in the United States estimated that 9.4 million adults ( $4 \%$ of the population) had seriously considered taking their own life in the previous 12 months, and 2.7 million (1\% of the population) made plans to do so, ${ }^{44}$ suggesting media reports of suicide have the potential to negatively influence many vulnerable people who might be swayed by news items.

We found that the size of the association for suicides after the reporting of deaths of celebrities by suicide was smaller than in a previous meta-analysis that included fewer studies and did not assess the risk of bias comprehensively (based on 10 studies). ${ }^{6}$ Reasons for the smaller association might include the broader literature search, exclusion of duplicate data, and exclusion of studies at critical risk of bias. A rate ratio of 8-18\% increase in suicide, however, highlights that media exposure relating to deaths of celebrities by suicide has a strong influence on the incidence of suicide in a population. In contrast, the global financial crisis of 2009 was associated with a $6 \%$ increase in suicide (although over a longer period of time). ${ }^{45}$ The estimated increase for reporting on deaths of celebrities by suicide might also underestimate the effects of media reporting on well known celebrities. Some of the studies included focused on individuals with questionable prominence, including mid-level or regional politicians and others not likely to be known by most of the population. ${ }^{11}$ Estimates were higher for well known celebrities, such as Robin Williams. Unlike in fixed effects meta-analyses of drug trials in defined populations, no true single effect exists for the association of media reporting on suicide with the number of subsequent suicides. Associations will probably vary depending on factors such as the prominence of the person in the media reports, the population's connection with that person, and the extent to which the death is reported responsibly by the media in the region where the study is conducted. The World Health Organization has emphasised that media professionals should be cautious when reporting on suicides in general and on deaths of celebrities by suicide in particular. ${ }^{16}$

For general reporting on suicide, taking into account all media reporting of suicide, no association with increases in the number of suicides was found. These studies usually evaluated the effect of the number of news articles on suicide on the next day or in the next week whereas studies of reporting on deaths of celebrities reported the presence or absence of a death of celebrity by suicide. The studies on general reporting of suicide also tended to use wide ranging search strategies to identify a broad variety of media reports related to suicide. This search strategy might have resulted in media reports associated with suicides but might have been distorted by inclusion of other reporting types that do not cause harm. Previous research suggests that not all reporting on suicide is associated with increases in the number of suicides. ${ }^{13}{ }^{14}$ The risk appears to vary with reporting characteristics. ${ }^{114}$ Increases are particularly likely for a subset of media reporting that describes suicide methods ${ }^{13}$; depicts suicide as inevitable ${ }^{14}$; or publicises false public myths about suicide. ${ }^{13}$ Some media reports on suicidal thoughts feature stories of hope and healing, rather than suicide attempts or deaths, and might help to prevent suicides (the so-called Papageno effect). ${ }^{134677}$ None of the studies in our meta-analysis considered the qualities of media reports based on media recommendations, and the variability in reporting qualities is likely large. Hence, a resulting underestimation of the effects for media stories that are inconsistent with media recommendations is possible. Future research should aim for a clear definition of the reporting to separate associations for different types of reports.

Our meta-analysis generally took a conservative approach by limiting the analysis to studies at moderate risk of bias and focusing entirely on total suicides (rather than subgroups) as the outcome for the primary analysis. If, for example, a study reported on the effects of news media reporting on the incidence of suicide in teenagers, the data extracted for our meta-analysis were for the total population, even if the study put a focus on its specific findings for the subgroup of teenagers. This approach was to ensure that selective reporting of findings in subgroups did not bias our estimates.

Like previous reviews, ${ }^{69}$ we found strong heterogeneity in risk estimates across studies on reporting of suicide by celebrities in particular. A large part of the heterogeneity was a result of the type of celebrity or number of celebrities analysed, suggesting that individuals best known to the public are those most likely to trigger more suicides. None of the characteristics explained the method specific increases in suicides. The remaining unexplained heterogeneity suggests that factors out of scope of our analysis might impact on the risk of increases in suicides after suicide reporting, including overall trends in the incidence of suicides in a country or over a period of time when media reporting occurs; socioeconomic conditions that might influence suicide reporting and imitation effects; and precise measurement of social identification with celebrities and other individuals who die by suicide.

We observed a number of significant and positive effect sizes and an absence of non-significant effect sizes in some regions of the funnel plots for studies of reporting on deaths of celebrities by suicide. This lack of symmetry could indicate publication bias. Many factors can contribute to asymmetry in funnel plots, however, and precise interpretation is difficult when the underlying evidence is based on observational data. ${ }^{48} 49$ Unpublished studies could have shown no association. If true, this means that our meta-analysis will have overestimated the association between media reporting of suicide by celebrities and subsequent suicides. A sensitivity analysis including studies with serious risk of bias indicated a similar pattern to the overall findings, suggesting that effect estimates for lower risk studies were similar.

\section{Strengths and limitations}

The strengths of our meta-analysis included its wide ranging systematic search strategy; screening of more studies than in 
previous quantitative meta-analyses on this topic; thorough check for duplicate data; and the comprehensive quality assessment of the primary studies. Our approach was intentionally conservative, focusing on studies with a low to moderate risk of bias and only with estimates related to total suicides in the population. This study also looks at the research on the effects of general reporting of suicide on subsequent numbers of suicides, although only five studies were available for this analysis.

Limitations included our inability to test causality because of the before-and-after and interrupted time series designs of the original studies, high levels of heterogeneity that could not be fully accounted for, and possible publication bias. Further, it was not possible to generate absolute risk estimates because the included studies mostly did not report the baseline risk of suicide in their respective settings. Despite the wide ranging search strategy, non-English language studies in the international literature might not have been indexed in the databases we searched. Our analysis covered only a proportion of suicide related media items. Studies on the effects of media items covering the spreading of novel suicide methods, such as charcoal burning in parts of Asia, ${ }^{50}$ were not included because of the low prevalence of these methods at baseline. Studies on fictional suicides were not included to avoid a further increase in heterogeneity between studies. Hence we cannot draw conclusions on these types of studies; our meta-analysis included studies with a narrower focus on interventions related to the reporting of suicide and suicidal behaviour. Finally, the only outcome considered in this meta-analysis was suicide. Although this outcome is of highest relevance to suicide prevention, media reports can impact on other domains as well, including help seeking behaviour and stigmatisation that have not been looked at in this meta-analysis. ${ }^{7}$

\section{Conclusions}

In this large and up-to-date systematic review and meta-analysis, we looked at the impact of suicide reports in news and information media on subsequent numbers of suicides. Our results support the continued use and promotion of guidelines on responsible media reporting of suicide, which are the best available interventions to address and prevent imitation effects in the population. ${ }^{15}{ }^{16}$ Collaboration between suicide prevention experts and media professionals in implementing these guidelines is an essential part of any suicide prevention strategy. Caution should be exercised in reporting suicides by celebrities in particular. The media will continue to report on newsworthy suicides but have a social responsibility to mitigate the likelihood of the Werther effect.

\section{What is already known on this topic}

National suicide prevention strategies include guidelines on responsible reporting of suicide but some journalists and editors are unconvinced, and high quality, up-to-date analyses of the research are lacking

Two previous meta-analyses examined the effect of reporting of deaths of celebrities by suicide on the incidence of suicide but did not extract quantitative estimates or focused on a small number of studies of unknown quality

A quantitative summary of the effect of general reporting on suicide on the incidence of suicide is lacking, despite these types of media reports being common

\section{What this study adds}

Reporting of deaths of celebrities by suicide appears to increase the number of suicides by $8-18 \%$ in the next $1-2$ months, and information on method of suicide was associated with an increase of $18-44 \%$ in the risk of suicide by the same method

General reporting of suicide does not appear to be associated with suicide although associations for some types of reporting cannot be ruled out

This study provides the clearest evidence so far that reporting on suicide, especially suicides by celebrities, is associated with increases in suicide in the general population

We thank Michiko Ueda, Feng Chen, and Shu-Sen Chang who reanalysed data from their studies for the meta-analysis.

Contributors: Substantial contributions to the conception or design of the work (MJS, TN, and JP); acquisition of the data (JP, BT, MB, SS, TN, and MJS); data extraction (MJS, TN, and MB); statistical analyses (MJS); interpretation of the data (all authors); drafting the work (TN, MJS, and MS); revising it critically for important intellectual content (all authors); final approval of the version to be published (all authors); agreement to be accountable for all aspects of the work (all authors). The corresponding author attests that all listed authors meet authorship criteria and that no others meeting the criteria have been omitted. TN and MJS act as guarantors.

Funding: No specific funding for this study. MB is funded by the Austrian Science Fund (FWF), grant No KLI627-B30. MJS is a recipient of an Australian Research Council Future Fellowship (project No FT180100075) funded by the Australian Government. The funding sources had no role in the design and conduct of the study; collection, management, analysis, and interpretation of the data; preparation, review, or approval of the manuscript; and decision to submit the manuscript for publication.

Competing interests: All authors have completed the ICMJE uniform disclosure form at www.icmje.org/coi_disclosure.pdf and declare: no support from any organisation for the submitted work; no financial relationships with any organisations that might have an interest in the submitted work in the previous three years; no other relationships or activities that could appear to have influenced the submitted work.

Ethical approval: Not required.

Data sharing: No additional data available.

The lead author affirms that the manuscript is an honest, accurate, and transparent account of the study being reported; that no important aspects of the study have been omitted; and that any discrepancies from the study as originally planned (and, if relevant, registered) have been explained.

Dissemination to participants and related patient and public communities: The study findings will be disseminated via conference presentations, press releases, and social media. A companion opinion article in The $B M J$ will serve to further stimulate discussion on the research. The authors will also disseminate findings to media organisations and press councils, and also national and international health organisations that have been instrumental in the development of media recommendations for suicide reporting. The wider public will be informed via media and in lectures and seminars on suicide prevention that target the broader public. Discussions on how the findings will be used to the benefit of the community will involve media professionals, individuals with personal experience of suicidal ideation or suicide attempt, individuals with experience of bereavement from suicide, mental health professionals, and the broader interested public. 
1 Pirkis J, Dare A, Blood RW, etal . Changes in media reporting of suicide in Australia between 2000/01 and 2006/07. Crisis 2009;30:25-33.

10.1027/0227-5910.30.1.25 19261565

2 Choi YJ, Oh H. Does media coverage of a celebrity suicide trigger copycat suicides? Evidence from Korean cases. $J$ Media Econ 2016;29:92-10510.1080/08997764.2016.1170020

3 Hagihara A, Tarumi K, Abe T. Media suicide-reports, Internet use and the occurrence of suicides between 1987 and 2005 in Japan. BMC Public Health 2007;7:321. 10.1186/1471-2458-7-321 17996117

4 Cheng Q, Chen F, Yip PSF. Media effects on suicide methods: a case study on Hong Kong 1998-2005. PLoS One 2017;12:e0175580. 10.1371/journal.pone.0175580 28403231

5 Gould MS, Kleinman MH, Lake AM, Forman J, Midle JB. Newspaper coverage of suicide and initiation of suicide clusters in teenagers in the USA, 1988-96: a retrospective, population-based, case-control study. Lancet Psychiatry 2014:1:34-43. 10.1016/S2215-0366(14)70225-1 26360401

6 Niederkrotenthaler T, Fu KW, Yip PSF, etal . Changes in suicide rates following media reports on celebrity suicide: a meta-analysis. $J$ Epidemiol Community Health 2012;66:1037-42. 10.1136/jech-2011-200707 22523342

7 Niederkrotenthaler T, Reidenberg DJ, Till B, Gould MS. Increasing help-seeking and referrals for individuals at risk for suicide by decreasing stigma: the role of mass media. Am J Prev Med 2014:47(Suppl 2):S235-43. 10.1016/j.amepre.2014.06.010 25145745

8 Pirkis J, Blood RW. Suicide and the media. Part I: Reportage in nonfictional media. Crisis 2001;22:146-54. 10.1027//0227-5910.22.4.146 11848658

9 Stack S. Suicide in the media: a quantitative review of studies based on nonfictional stories. Suicide Life Threat Behav 2005;35:121-33. 10.1521/suli.35.2.121.62877 15843330

10 Niederkrotenthaler T, Stack S. Media and suicide: international perspectives on research, theory, and policy. Routledge, 2017.

11 Phillips DP. The influence of suggestion on suicide: substantive and theoretical implications of the Werther effect. Am Sociol Rev 1974;39:340-54. 10.2307/2094294 11630757

12 Sudak HS, Sudak DM. The media and suicide. Acad Psychiatry 2005;29:495-9. 10.1176/appi.ap.29.5.495 16387977

13 Niederkrotenthaler T, Voracek M, Herberth A, etal . Role of media reports in completed and prevented suicide: Werther v. Papageno effects. Br J Psychiatry 2010;197:234-43. 10.1192/bjp.bp.109.074633 20807970

14 Sinyor M, Schaffer A, Nishikawa Y, etal . The association between suicide deaths and putatively harmful and protective factors in media reports. CMAJ 2018;190:E900-7. 10.1503/cmaj. 17069830061324

15 World Health Organization (WHO). Preventing suicide: a global imperative. World Health Organization, 2014

16 World Health Organization (WHO). Preventing suicide: a resource for media professionals - update 2017. World Health Organization, 2017.

17 Carmichael V, Whitley R. Media coverage of Robin Williams' suicide in the United States: A contributor to contagion?PLoS One 2019;14:e216543. 10.1371/journal.pone.0216543 31071144

18 Creed M, Whitley R. Assessing fidelity to suicide reporting guidelines in Canadian news media: the death of Robin Williams. Can J Psychiatry 2017;62:313-7. 10.1177/0706743715621255 27600531

19 Baron JN, Reiss PC. Same time, next year: aggregate analyses of the mass media and violent behavior. Am Sociol Rev 1985;50:347-6310.2307/2095544

20 Sinyor M, Pirkis J, Picard A, etal . Towards a shared understanding: Perspectives from Toronto's first media forum for suicide prevention. Can J Public Health 2016;107:e330-2. 10.17269/CJPH.107.5437 27763851

21 Till B, Niederkrotenthaler T. Surfing for suicide methods and help: content analysis of websites retrieved with search engines in Austria and the United States. $J$ Clin Psychiatry 2014;75:886-92. 10.4088/JCP.13m08861 25099284

22 Falagas ME, Pitsouni El, Malietzis GA, Pappas G. Comparison of PubMed, Scopus, Web of Science, and Google Scholar: strengths and weaknesses. FASEB J 2008;22:338-42. 10.1096/fj.07-9492LSF 17884971

23 Haddaway NR, Collins AM, Coughlin D, Kirk S. The role of Google Scholar in evidence reviews and its applicability to grey literature searching. PLOS One 2015;10:e0138237. 10.1371/journal.pone.0138237 26379270

24 Fu KW, Yip PSF. Long-term impact of celebrity suicide on suicidal ideation: results from a population-based study. J Epidemiol Community Health 2007;61:540-6. 10.1136/jech.2005.045005 17496264

25 Thiese MS. Observational and interventional study design types; an overview. Biochem Med (Zagreb) 2014;24:199-210. 10.11613/BM.2014.022 24969913

26 Schmidt WP. Randomised and non-randomised studies to estimate the effect of community-level public health interventions: definitions and methodological considerations. Emerg Themes Epidemiol 2017;14:9. 10.1186/s12982-017-0063-5 28912825

27 Handley MA, Lyles CR, McCulloch C, Cattamanchi A. Selecting and improving design in effectiveness and implementation research. Annu Rev Public Health 2018;39:5-25. 10.1146/annurev-publhealth-040617-014128 29328873

28 Kontopantelis E, Doran T, Springate DA, Buchan I, Reeves D. Regression based quasi-experimental approach when randomisation is not an option: interrupted time series analysis. BMJ 2015;350:h2750. 10.1136/bmj.h2750 26058820
29 Sterne JAC, Hernán MA, Reeves BC, etal . ROBINS-I: a tool for assessing risk of bias in non-randomised studies of interventions. BMJ 2016:355:14919. 10.1136/bmj.i4919 27733354

30 Thomson H, Craig P, Hilton-Boon M, Campbell M, Katikireddi SV. Applying the ROBINS-I tool to natural experiments: an example from public health. Syst Rev 2018;7:15. 10.1186/s13643-017-0659-4 29368630

31 Sterne JAC, Hernán MA, McAleenan A. 25.5 Risk of bias in uncontrolled before-after studies (including interrupted time series), 25: Assessing risk of bias in a non-randomized study. In: Higgins JPT, Green S, eds. Cochrane handbook for systematic reviews of interventions. 6th ed. 2019. https://training.cochrane.org/handbook/current/chapter-25\# section-25-5.

32 Knapp G, Hartung J. Improved tests for a random effects meta-regression with a single covariate. Stat Med 2003;22:2693-710. 10.1002/sim.1482 12939780

33 Higgins JPT, Thompson SG. Quantifying heterogeneity in a meta-analysis. Stat Med 2002;21:1539-58. 10.1002/sim.1186 12111919

34 Peters JL, Sutton AJ, Jones DR, Abrams KR, Rushton L. Contour-enhanced meta-analysis funnel plots help distinguish publication bias from other causes of asymmetry. J Clin Epidemiol 2008;61:991-6. 10.1016/j.jclinepi.2007.11.010 18538991

35 Egger M, Davey Smith G, Schneider M, Minder C. Bias in meta-analysis detected by a simple, graphical test. BMJ 1997;315:629-34. 10.1136/bmj.315.7109.629 9310563

36 Pirkis J, Currier D, Too LS, etal . Suicides in Australia following media reports of the death of Robin Williams. Aust N Z J Psychiatry 2020;54:99-104. $10.1177 / 000486741988829731749369$

37 Stack S. Social correlates of suicide by age: media impacts. In: Leenaars AA, ed. Life span perspectives of suicide. Plenum Press, 1991: 187-21310.1007/978-1-4899-0724-0_14

38 Niederkrotenthaler T, Till B, Kapusta ND, Voracek M, Dervic K, Sonneck G. Copycat effects after media reports on suicide: a population-based ecologic study. Soc Sci Med 2009;69:1085-90. 10.1016/j.socscimed.2009.07.041 19682782

39 Dyer R, McDonald P. Stars. British Film Institute, 1998.

40 Pouliot L, Mishara BL, Labelle R. The Werther effect reconsidered in light of psychological vulnerabilities: results of a pilot study. J Affect Disord 2011;134:488-96. 10.1016/.j.jad.2011.04.050 21621270

41 Till B, Vitouch P, Herberth A, Sonneck G, Niederkrotenthaler T. Personal suicidality in reception and identification with suicidal film characters. Death Stud 2013;37:383-92. 10.1080/07481187.2012.67353124520893

42 Till B, Strauss M, Sonneck G, Niederkrotenthaler T. Determining the effects of films with suicidal content: a laboratory experiment. Br J Psychiatry 2015;207:72-8. 10.1192/bjp.bp.114.152827 25906792

43 Nock MK, Borges G, Bromet EJ, etal . Cross-national prevalence and risk factors for suicidal ideation, plans and attempts. Br J Psychiatry 2008;192:98-105. 10.1192/bjp.bp.107.040113 18245022

44 Lipari R, Piscopo K, Kroutil LA, Kilmer Miller G. NSDUH data review: suicidal thoughts and behavior among adults - results from the 2014 national survey on drug use and health Substance Abuse and Mental Health Services Administration, 2015. https://www.samhsa. gov/data/sites/default/files/NSDUH-FRR2-2014/NSDUH-FRR2-2014.pdf.

45 Sinyor M, Tse R, Pirkis J. Global trends in suicide epidemiology. Curr Opin Psychiatry 2017;30:1-6. 10.1097/YCO.0000000000000296 27845946

46 Till B, Arendt F, Scherr S, Niederkrotenthaler T. Effect of educative suicide prevention news articles featuring experts with vs without personal experience of suicidal ideation: a randomized controlled trial of the Papageno effect. J Clin Psychiatry 2018;80:17m11975 10.4088/JCP.17m11975 30549483

47 Niederkrotenthaler T, Till B. Effects of suicide awareness materials on individuals with recent suicidal ideation or attempt: online randomised controlled trial. Br J Psychiatry 2019. 10.1192/bjp.2019.259 31843026

48 Egger M, Schneider M, Davey Smith G. Spurious precision? Meta-analysis of observational studies. BMJ 1998:316:140-4. 10.1136/bmi.316.7125.140 9462324

49 Sterne JAC, Sutton AJ, loannidis JPA, etal . Recommendations for examining and interpreting funnel plot asymmetry in meta-analyses of randomised controlled trials. $B M J$ 2011;343:d4002. 10.1136/bmj.d4002 21784880

50 Lee AR, Ahn MH, Lee TY, Park S, Hong JP. Rapid spread of suicide by charcoal burning from 2007 to 2011 in Korea [correction in: Psychiatry Res 2015;227:73]. Psychiatry Res 2014;219:518-24. 10.1016/.jpsychres.2014.06.037 25048757

\section{Accepted: 04022020}

(c) Author(s) (or their employer(s)) 2019. Re-use permitted under CC BY-NC. No commercial re-use. See rights and permissions. Published by BMJ.http://creativecommons.org/licenses/by-nc/4.0/This is an Open Access article distributed in accordance with the Creative Commons Attribution Non Commercial (CC BY-NC 4.0) license, which permits others to distribute, remix, adapt, build upon this work non-commercially, and license their derivative works on different terms, provided the original work is properly cited and the use is non-commercial. See: http://creativecommons. org/licenses/by-nc/4.0/. 


\section{Tables}

\section{Table 1| Characteristics of included studies, Bakst to Koburger}

\begin{tabular}{|c|c|c|c|c|c|c|c|c|c|c|c|c|}
\hline $\begin{array}{l}\text { Author and } \\
\text { year }\end{array}$ & Country & Study period* & $\begin{array}{l}\text { Study } \\
\text { length }\end{array}$ & $\begin{array}{l}\text { Follow-up } \\
\text { time }\end{array}$ & Outcome & $\begin{array}{l}\text { Intervention } \\
\text { measured }\end{array}$ & Celebrity & $\begin{array}{c}\text { No of } \\
\text { interventions } \\
\text { / celebrities§ }\end{array}$ & $\begin{array}{l}\text { Celebrity } \\
\text { type }\end{array}$ & $\begin{array}{l}\text { Celebrity } \\
\text { recognition }\end{array}$ & $\begin{array}{l}\text { Total } \\
\text { suicides } \\
\text { and } \\
\text { specific } \\
\text { suicide } \\
\text { method }\end{array}$ & $\begin{array}{l}\text { Media } \\
\text { type }^{\star \star}\end{array}$ \\
\hline Bakst 2018 & Israel & $2008-12$ & $\begin{array}{c}40 \\
\text { weeks }\end{array}$ & 4 weeks & $\begin{array}{l}\text { Daily } \\
\text { counts } \\
\text { aggregate } \\
\text { to } 28 \text { days }\end{array}$ & Binary† & Yes & 5 ๆ & Mixed & Local & $\begin{array}{c}\text { Total } \\
\text { suicides }\end{array}$ & Mixed \\
\hline Chang 2015 & Taiwan & $2008-11$ & $\begin{array}{c}179 \\
\text { weeks }\end{array}$ & Next week & $\begin{array}{l}\text { Weekly } \\
\text { counts }\end{array}$ & Continuous $\ddagger$ & No & 6444 & - & - & $\begin{array}{c}\text { Total } \\
\text { suicides }\end{array}$ & Newspap \\
\hline Chen 2011 & Taiwan & $\begin{array}{l}\text { May 2003-December } \\
2005\end{array}$ & $\begin{array}{l}975 \\
\text { days }\end{array}$ & 1 day & $\begin{array}{l}\text { Daily } \\
\text { counts }\end{array}$ & Continuousł & No & 5088 & - & - & $\begin{array}{c}\text { Total } \\
\text { suicides }\end{array}$ & Newspar \\
\hline Chen 2012 & Taiwan & 2006-08 & $\begin{array}{c}156 \\
\text { weeks }\end{array}$ & 2 weeks & $\begin{array}{l}\text { Weekly } \\
\text { counts }\end{array}$ & Binary $†$ & Yes & $1 \rrbracket$ & Entertainer & Local & $\begin{array}{l}\text { Total } \\
\text { suicides } \\
\text { and by } \\
\text { charcoal } \\
\text { burning }\end{array}$ & Mixed \\
\hline Chen 2013 & Taiwan & 1998-02 & $\begin{array}{l}1825 \\
\text { days }\end{array}$ & 1 day & $\begin{array}{l}\text { Daily } \\
\text { counts }\end{array}$ & Continuousł & No & 5253 & - & - & $\begin{array}{c}\text { Total } \\
\text { suicides }\end{array}$ & Newspa \\
\hline Cheng 2007 & Taiwan & $2003-05$ & $\begin{array}{c}156 \\
\text { weeks }\end{array}$ & 4 weeks & $\begin{array}{l}\text { Weekly } \\
\text { counts }\end{array}$ & Binary† & Yes & $1 \rrbracket$ & Entertainer & Local & $\begin{array}{l}\text { Total } \\
\text { suicides } \\
\text { and by } \\
\text { hanging }\end{array}$ & Mixed \\
\hline Cheng 2017 & Hong Kong & 1998-2005 & $\begin{array}{l}2678 \\
\text { days }\end{array}$ & 1 day & Daily count & Continuous $\ddagger$ & No & 6308 & - & - & $\begin{array}{c}\text { Total } \\
\text { suicides }\end{array}$ & Newspa \\
\hline Choi 2016 & South Korea & 1997-2009 & $\begin{array}{c}155 \\
\text { months }\end{array}$ & 1 month & $\begin{array}{l}\text { Monthly } \\
\text { counts }\end{array}$ & Continuous $\ddagger$ & Yes & 159 & Mixed & Local & $\begin{array}{c}\text { Total } \\
\text { suicides }\end{array}$ & Mixed \\
\hline $\begin{array}{l}\text { Etzersdorfer } \\
2004\end{array}$ & Austria & $1981-99$ & $\begin{array}{c}114 \\
\text { weeks }\end{array}$ & 3 weeks & $\begin{array}{c}\text { Daily } \\
\text { counts } \\
\text { aggregated } \\
\text { to } 3 \text { week } \\
\text { periods }\end{array}$ & Binary† & Yes & 19 & $\begin{array}{l}\text { Hotel } \\
\text { owner }\end{array}$ & Local & $\begin{array}{l}\text { Total } \\
\text { suicides } \\
\text { and by } \\
\text { firearm }\end{array}$ & Newspa \\
\hline Fink 2018 & USA & 1999-2014 & $\begin{array}{c}189 \\
\text { months }\end{array}$ & $\begin{array}{l}2 \text { months } \\
\text { (same } \\
\text { month and } \\
\text { next month) }\end{array}$ & $\begin{array}{l}\text { Monthly } \\
\text { counts }\end{array}$ & Binary† & Yes & $1 \rrbracket$ & Entertainer & International & $\begin{array}{l}\text { Total } \\
\text { suicides } \\
\text { and by } \\
\text { hanging }\end{array}$ & Mixed \\
\hline Fu 2009 & Hong Kong & 2001-03 & $\begin{array}{c}156 \\
\text { weeks }\end{array}$ & 4 weeks & $\begin{array}{l}\text { Weekly } \\
\text { counts }\end{array}$ & Binary $†$ & Yes & $1 \rrbracket$ & Entertainer & Local & $\begin{array}{l}\text { Total } \\
\text { suicides } \\
\text { and by } \\
\text { jumping }\end{array}$ & Mixed \\
\hline $\begin{array}{l}\text { Hagihara } \\
2007\end{array}$ & Japan & $1987-2005$ & $\begin{array}{c}218 \\
\text { months }\end{array}$ & Next month & $\begin{array}{l}\text { Monthly } \\
\text { count }\end{array}$ & Continuousł & No & $\begin{array}{c}480 \times 10^{6} \text { per } \\
\text { month†† }\end{array}$ & - & - & $\begin{array}{c}\text { Total } \\
\text { suicides }\end{array}$ & Newspap \\
\hline Jobes 1996 & USA & 1993-95 & $\begin{array}{c}36 \\
\text { weeks }\end{array}$ & $\begin{array}{l}7 \text { weeks } \\
\text { including } \\
\text { the week of } \\
\text { intervention }\end{array}$ & $\begin{array}{l}\text { Weekly } \\
\text { counts }\end{array}$ & Binary† & Yes & $1 \rrbracket$ & Entertainer & International & $\begin{array}{c}\text { Total } \\
\text { suicides }\end{array}$ & Mixed \\
\hline Jonas 1992 & Germany & $1968-80$ & $\begin{array}{l}4748 \\
\text { days }\end{array}$ & 7 days & $\begin{array}{l}\text { Daily } \\
\text { counts }\end{array}$ & Binary $\dagger$ & Yes & $14 \pi$ & Mixed & Mixed & $\begin{array}{c}\text { Total } \\
\text { suicides }\end{array}$ & Mixed \\
\hline $\begin{array}{l}\text { Kessler } \\
1989\end{array}$ & USA & $1973-84$ & $\begin{array}{l}4383 \\
\text { days }\end{array}$ & 8 days & $\begin{array}{l}\text { Daily } \\
\text { counts }\end{array}$ & Binary† & No & 87 & - & - & $\begin{array}{c}\text { Total } \\
\text { suicides }\end{array}$ & Televisior \\
\hline $\begin{array}{l}\text { Koburger } \\
2015\end{array}$ & $\begin{array}{c}\text { Austria, } \\
\text { Hungary, the } \\
\text { Netherlands, } \\
\text { Slovenia }\end{array}$ & $\begin{array}{l}\text { September-November } \\
2009\end{array}$ & $\begin{array}{c}10 \\
\text { weeks }\end{array}$ & 2 weeks & $\begin{array}{l}\text { Weekly } \\
\text { counts from } \\
4 \text { countries }\end{array}$ & Binary† & Yes & 19 & Sports & International & $\begin{array}{l}\text { Railway } \\
\text { suicides }\end{array}$ & Mixed \\
\hline
\end{tabular}

* Time frame when outcome data were selected.

† Period of intervention.

$\ddagger$ Number of media reports of suicide. 


\section{Table 1 (continued)}

\begin{tabular}{|c|c|c|c|c|c|c|c|c|c|c|c|c|}
\hline $\begin{array}{l}\text { Author and } \\
\text { year }\end{array}$ & Country & Study period ${ }^{\star}$ & $\begin{array}{l}\text { Study } \\
\text { length }\end{array}$ & $\begin{array}{l}\text { Follow-up } \\
\text { time }\end{array}$ & Outcome & $\begin{array}{l}\text { Intervention } \\
\text { measured }\end{array}$ & Celebrity & $\begin{array}{c}\text { No of } \\
\text { interventions } \\
\text { / celebrities§ }\end{array}$ & $\begin{array}{l}\text { Celebrity } \\
\text { type }\end{array}$ & $\begin{array}{l}\text { Celebrity } \\
\text { recognition }\end{array}$ & $\begin{array}{c}\text { Total } \\
\text { suicides } \\
\text { and } \\
\text { specific } \\
\text { suicide } \\
\text { method }\end{array}$ & $\begin{array}{l}\text { Media } \\
\text { type }^{\star \star}\end{array}$ \\
\hline
\end{tabular}

$\S$ Number of celebrities ( $(\mathbb{)})$ or number of interventions.

** For celebrities, media type is always assumed to be mixed (an exception is Etzersdofer et al 2004, which focused on an extraordinary series of reports in one newspaper). $\mathrm{t}$ This measure has two components: number of articles on suicide in the four major newspapers and the circulation of those newspapers. 


\begin{tabular}{|c|c|c|c|c|c|c|c|c|c|c|c|c|}
\hline Author and year & Country & Study period ${ }^{*}$ & $\begin{array}{l}\text { Study } \\
\text { length }\end{array}$ & $\begin{array}{l}\text { Follow-up } \\
\text { time }\end{array}$ & Outcome & $\begin{array}{c}\text { Intervention } \\
\text { measured }\end{array}$ & Celebrity & $\begin{array}{c}\text { No of } \\
\text { interventions } \\
\text { / celebrities§ }\end{array}$ & $\begin{array}{c}\text { Celebrity } \\
\text { type }\end{array}$ & $\begin{array}{l}\text { Celebrity } \\
\text { recognition }\end{array}$ & $\begin{array}{c}\text { Total } \\
\text { suicides } \\
\text { and } \\
\text { specific } \\
\text { suicide } \\
\text { method }\end{array}$ & 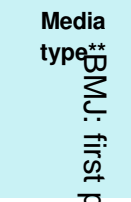 \\
\hline Koepping 1989 & $\begin{array}{l}\text { The } \\
\text { Netherlands }\end{array}$ & $1974-84$ & $\begin{array}{l}4018 \\
\text { days }\end{array}$ & $\begin{array}{l}7 \text { days } \\
\text { (including } \\
\text { day } 0 \text { ) }\end{array}$ & Daily count & Binary $†$ & No & 126 & - & - & $\begin{array}{l}\text { Total } \\
\text { suicides }\end{array}$ & 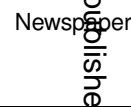 \\
\hline Ladwig 2012 & Germany & $\begin{array}{c}\text { October-December } \\
2009\end{array}$ & 56 days & 28 days & $\begin{array}{l}\text { Daily } \\
\text { counts } \\
\text { aggregated } \\
\text { over the } \\
\text { follow-up } \\
\text { period }\end{array}$ & Binary $\dagger$ & Yes & 19 & Sports & International & $\begin{array}{l}\text { Railway } \\
\text { suicides }\end{array}$ & 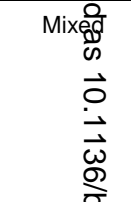 \\
\hline Lee 2019 & South Korea & 2007-15 & $\begin{array}{c}164 \\
\text { fortnights }\end{array}$ & 2 weeks & $\begin{array}{c}\text { Daily } \\
\text { counts } \\
\text { aggregated } \\
\text { to } 2 \text { week } \\
\text { periods }\end{array}$ & Binary $\dagger$ & Yes & $69 \pi$ & Mixed & $\begin{array}{l}\text { Mixed, more } \\
\text { local }\end{array}$ & $\begin{array}{l}\text { Total } \\
\text { suicides }\end{array}$ & 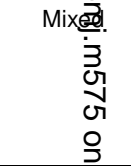 \\
\hline Mockus 2018 & USA & $1973-88$ & $\begin{array}{l}5844 \\
\text { days }\end{array}$ & $\begin{array}{c}3 \text { days } \\
\text { including } \\
\text { day } 0\end{array}$ & $\begin{array}{c}\text { Daily } \\
\text { counts }\end{array}$ & Binary $\dagger$ & Yes & $11 \rrbracket$ & Mixed & $\begin{array}{l}\text { Mixed, more } \\
\text { local }\end{array}$ & $\begin{array}{c}\text { Total } \\
\text { suicides }\end{array}$ & 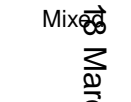 \\
\hline $\begin{array}{l}\text { Niederkrotenthaler } \\
2009\end{array}$ & Austria & $1996-2006$ & 896 days & 28 days & $\begin{array}{c}\text { Daily } \\
\text { counts } \\
\text { aggregated } \\
\text { to } 28 \text { day } \\
\text { period }\end{array}$ & Binary & Yes & 169 & Mixed & Mixed & $\begin{array}{c}\text { Total } \\
\text { suicides } \\
\text { and } \\
\text { mixed } \\
\text { suicide } \\
\text { methods }\end{array}$ & $\begin{array}{c}\text { Mixeet } \\
\text { O } \\
\text { N } \\
0 \\
\square \\
\text { O } \\
\vdots\end{array}$ \\
\hline Phillips 1974 & USA & $1947-68$ & $\begin{array}{c}102 \\
\text { months }\end{array}$ & $\begin{array}{c}\text { Same } \\
\text { month or } \\
\text { next month } \\
\text { depending } \\
\text { on } \\
\text { intervention } \\
\text { date }\end{array}$ & $\begin{array}{l}\text { Monthly } \\
\text { counts }\end{array}$ & Binary† & Yes & $34 \pi$ & Mixed & $\begin{array}{l}\text { Mixed, more } \\
\quad \text { local }\end{array}$ & $\begin{array}{c}\text { Total } \\
\text { suicides }\end{array}$ & 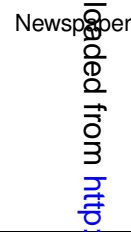 \\
\hline Pirkis 2020 & Australia & 2001-16 & $\begin{array}{l}5845 \\
\text { days }\end{array}$ & 2 months & $\begin{array}{c}\text { Daily } \\
\text { counts }\end{array}$ & Binary & Yes & $1 \pi$ & Entertainer & International & $\begin{array}{c}\text { Total } \\
\text { suicides } \\
\text { and by } \\
\text { hanging }\end{array}$ & Mixes \\
\hline Queinec 2011 & France & $1979-2006$ & $\begin{array}{c}10227 \\
\text { days }\end{array}$ & 30 days & $\begin{array}{c}\text { Daily } \\
\text { counts } \\
\text { aggregated } \\
\text { to months }\end{array}$ & Binary & Yes & 69 & Mixed & $\begin{array}{l}\text { Mixed, more } \\
\text { local }\end{array}$ & $\begin{array}{c}\text { Total } \\
\text { suicides } \\
\text { and } \\
\text { mixed } \\
\text { suicide } \\
\text { methods } \\
\end{array}$ & 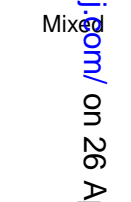 \\
\hline Romer 2006 & USA & July-October 1993 & 123 days & 10 days & $\begin{array}{l}\text { Daily } \\
\text { counts }\end{array}$ & Continuous $\ddagger$ & No & 125 & - & - & $\begin{array}{c}\text { Total } \\
\text { suicides }\end{array}$ & Mixe \\
\hline Ruddigkeit 2010 & Germany & 2001-03 & $\begin{array}{c}156 \\
\text { weeks }\end{array}$ & 1 week & $\begin{array}{c}\text { Daily } \\
\text { counts } \\
\text { aggregated } \\
\text { to weeks }\end{array}$ & Binary $\dagger$ & No & 143 & - & - & $\begin{array}{c}\text { Total } \\
\text { suicides }\end{array}$ & $\begin{array}{c}\text { Newspāper } \\
\underset{\sigma}{\sigma} \\
\frac{0}{0}\end{array}$ \\
\hline Schafer 2015 & Germany & $1992-2009$ & 90 weeks & 4 weeks & $\begin{array}{l}\text { Daily } \\
\text { counts } \\
\text { aggregated } \\
\text { to weeks }\end{array}$ & Binary† & Yes & 69 & Mixed & $\begin{array}{l}\text { Mixed, more } \\
\text { local }\end{array}$ & $\begin{array}{l}\text { Total } \\
\text { suicides } \\
\text { and } \\
\text { mixed } \\
\text { suicide } \\
\text { methods } \\
\end{array}$ & 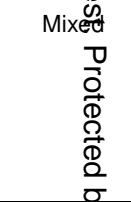 \\
\hline Stack 1996 & Japan & $1955-85$ & $\begin{array}{c}372 \\
\text { months }\end{array}$ & $\begin{array}{c}\text { Same } \\
\text { month or } \\
\text { next month } \\
\text { depending } \\
\text { on } \\
\text { intervention } \\
\text { date }\end{array}$ & $\begin{array}{l}\text { Monthly } \\
\text { counts }\end{array}$ & Binary & Yes & $24 \pi$ & Mixed & Mixed & $\begin{array}{c}\text { Total } \\
\text { suicides }\end{array}$ & Mixe्ठู \\
\hline
\end{tabular}


Table 2 (continued)

\begin{tabular}{|c|c|c|c|c|c|c|c|c|c|c|c|}
\hline Author and year & Country & Study period* & $\begin{array}{l}\text { Study } \\
\text { length }\end{array}$ & $\begin{array}{l}\text { Follow-up } \\
\text { time }\end{array}$ & Outcome & $\begin{array}{l}\text { Intervention } \\
\text { measured }\end{array}$ & Celebrity & $\begin{array}{c}\text { No of } \\
\text { interventions } \\
\text { / celebrities§ }\end{array}$ & $\begin{array}{l}\text { Celebrity } \\
\text { type }\end{array}$ & $\begin{array}{c}\text { Celebrity } \\
\text { recognition }\end{array}$ & $\begin{array}{c}\text { Total } \\
\text { suicides } \\
\text { and } \\
\text { specific } \\
\text { suicide } \\
\text { method }\end{array}$ \\
\hline Ueda 2014 & Japan & $1989-2010$ & $\begin{array}{l}8035 \\
\text { days }\end{array}$ & 10 days & $\begin{array}{l}\text { Daily } \\
\text { counts }\end{array}$ & Binary† & Yes & 1099 & Mixed & Local & $\begin{array}{c}\text { Total } \\
\text { suicides }\end{array}$ \\
\hline Ueda 2017 & Japan & $2010-14$ & $\begin{array}{l}1645 \\
\text { days }\end{array}$ & 10 days & $\begin{array}{l}\text { Daily } \\
\text { counts }\end{array}$ & Binary† & Yes & $26 \rrbracket$ & Mixed & Local & $\begin{array}{c}\text { Total } \\
\text { suicides }\end{array}$ \\
\hline Whitley 2019 & Canada & $1999-2015$ & $\begin{array}{c}189 \\
\text { months }\end{array}$ & $\begin{array}{l}2 \text { months } \\
\text { (same } \\
\text { month and } \\
\text { next month) }\end{array}$ & $\begin{array}{l}\text { Monthly } \\
\text { counts }\end{array}$ & Binary† & Yes & 19 & Entertainer & International & $\begin{array}{c}\text { Total } \\
\text { suicides } \\
\text { and by } \\
\text { hanging }\end{array}$ \\
\hline \multicolumn{12}{|c|}{ * Time frame when outcome data were selected. } \\
\hline \multicolumn{12}{|c|}{ †Period of intervention. } \\
\hline \multicolumn{12}{|c|}{$\ddagger$ Number of media reports of suicide. } \\
\hline \multicolumn{12}{|c|}{$\S$ Number of celebrities $(\mathbb{\Upsilon})$ or number of interventions. } \\
\hline \multicolumn{12}{|c|}{${ }^{* *}$ For celebrities, media type is always assumed to be mixed. } \\
\hline
\end{tabular}




\begin{tabular}{|c|c|c|c|c|}
\hline Variable & No of studies & Rate ratio $(95 \% \mathrm{Cl})^{*}$ & $P$ value & $I^{2}(\%) \dagger$ \\
\hline \multicolumn{5}{|l|}{ Period published: } \\
\hline$\leq 2005$ & 2 & $1.12(0.99$ to 1.26$)$ & \multirow[t]{4}{*}{0.04} & \multirow[t]{4}{*}{29.1} \\
\hline $2006-10$ & 3 & $1.13(1.04$ to 1.23$)$ & & \\
\hline 2011-15 & 4 & $1.06(1.02$ to 1.10$)$ & & \\
\hline$\geq 2016$ & 5 & $1.16(1.11$ to 1.22$)$ & & \\
\hline \multicolumn{5}{|l|}{ Follow-up time: } \\
\hline$\leq 14$ days & 4 & 1.09 (1.02 to 1.18$)$ & \multirow[t]{2}{*}{0.30} & \multirow[t]{2}{*}{69.6} \\
\hline$\geq 15$ days & 10 & $1.14(1.09$ to 1.20$)$ & & \\
\hline \multicolumn{5}{|l|}{ Location: } \\
\hline Asia & 6 & $1.11(1.04$ to 1.18$)$ & \multirow[t]{3}{*}{0.20} & \multirow[t]{3}{*}{64.7} \\
\hline Europe & 5 & $1.09(1.03$ to 1.16$)$ & & \\
\hline North America/Australia & 3 & $1.18(1.10$ to 1.26$)$ & & \\
\hline \multicolumn{5}{|l|}{ Study design: } \\
\hline Multiple arm before-and-after comparison & 4 & $1.09(1.01$ to 1.17$)$ & \multirow[t]{2}{*}{0.20} & \multirow[t]{2}{*}{78.8} \\
\hline Interrupted time series analysis & 10 & 1.15 (1.09 to 1.21$)$ & & \\
\hline Study length (per 1000 days) & 14 & $1.00(0.99$ to 1.02$)$ & 0.83 & 78.8 \\
\hline \multicolumn{5}{|l|}{ Unit of analysis: } \\
\hline Day & 8 & $1.09(1.05$ to 1.14$)$ & \multirow[t]{3}{*}{0.06} & \multirow[t]{3}{*}{69.3} \\
\hline Week & 3 & $1.19(1.06$ to 1.33$)$ & & \\
\hline Month & 3 & $1.19(1.11$ to 1.28$)$ & & \\
\hline \multicolumn{5}{|l|}{ Adjustment for confounders: } \\
\hline No & 9 & $1.12(1.07$ to 1.17$)$ & \multirow[t]{2}{*}{0.40} & \multirow[t]{2}{*}{85.0} \\
\hline Yes & 5 & 1.17 (1.06 to 1.28$)$ & & \\
\hline \multicolumn{5}{|l|}{ Celebrity recognition: } \\
\hline Local & 7 & $1.12(1.04$ to 1.21$)$ & \multirow[t]{3}{*}{0.29} & \multirow[t]{3}{*}{80.8} \\
\hline International & 3 & 1.18 (1.09 to 1.27$)$ & & \\
\hline Mixed & 4 & 1.09 (1.02 to 1.17$)$ & & \\
\hline \multicolumn{5}{|l|}{ Celebrity type: } \\
\hline Entertainer & 6 & 1.17 (1.12 to 1.23$)$ & \multirow[t]{2}{*}{0.009} & \multirow[t]{2}{*}{47.9} \\
\hline Other & 8 & 1.08 (1.04 to 1.12$)$ & & \\
\hline \multicolumn{5}{|l|}{ No of celebrities: } \\
\hline 1 & 7 & $1.17(1.12$ to 1.23$)$ & \multirow[t]{2}{*}{0.009} & \multirow[t]{2}{*}{47.0} \\
\hline$\geq 2$ & 7 & $1.08(1.04$ to 1.12$)$ & & \\
\hline
\end{tabular}

${ }^{*}$ Rate ratios and $95 \%$ confidence intervals in each category were calculated with the exponential of the linear combination of coefficients from the meta-regression model.

† Heterogeneity remaining after meta-regression. 


\section{Figures}

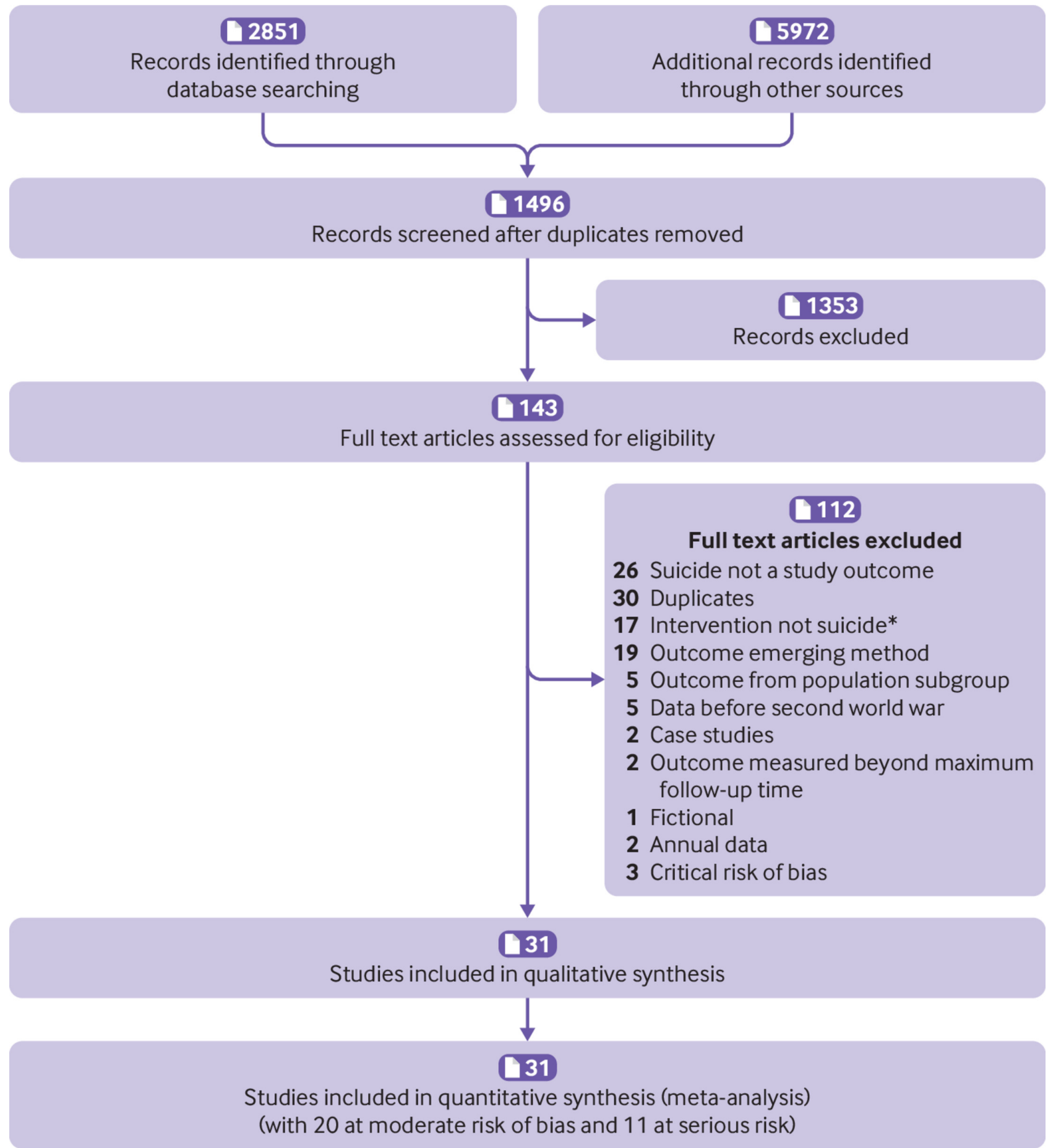

* Intervention not on media reporting or about reporting other than on suicide

Fig 1 Preferred reporting items for systematic reviews and meta-analyses (PRISMA) flow diagram 


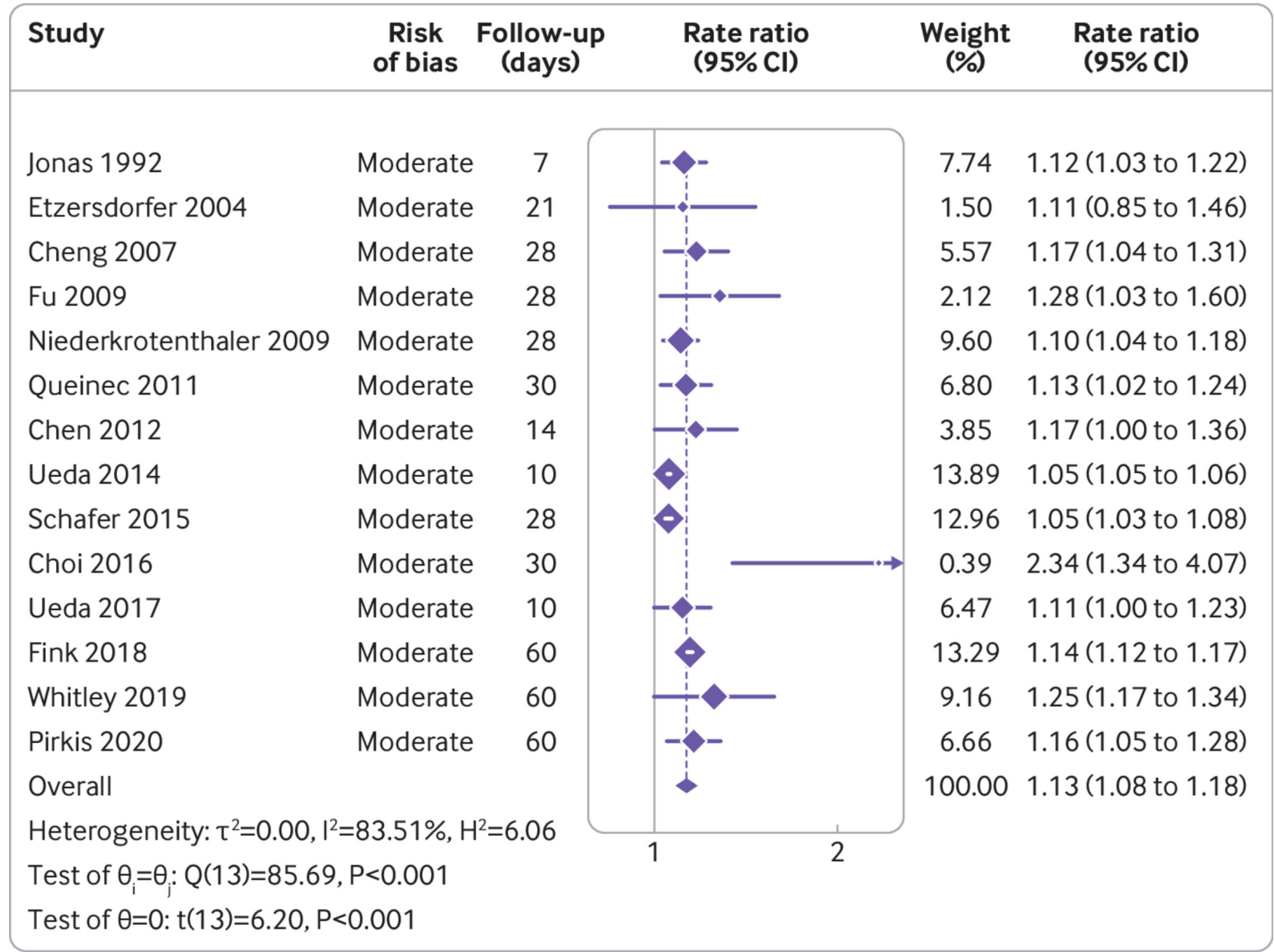

Random effects REML model Knapp-Hartung standard errors

Fig 2 Forest plot for primary analysis: media reporting of deaths of celebrities by suicide 


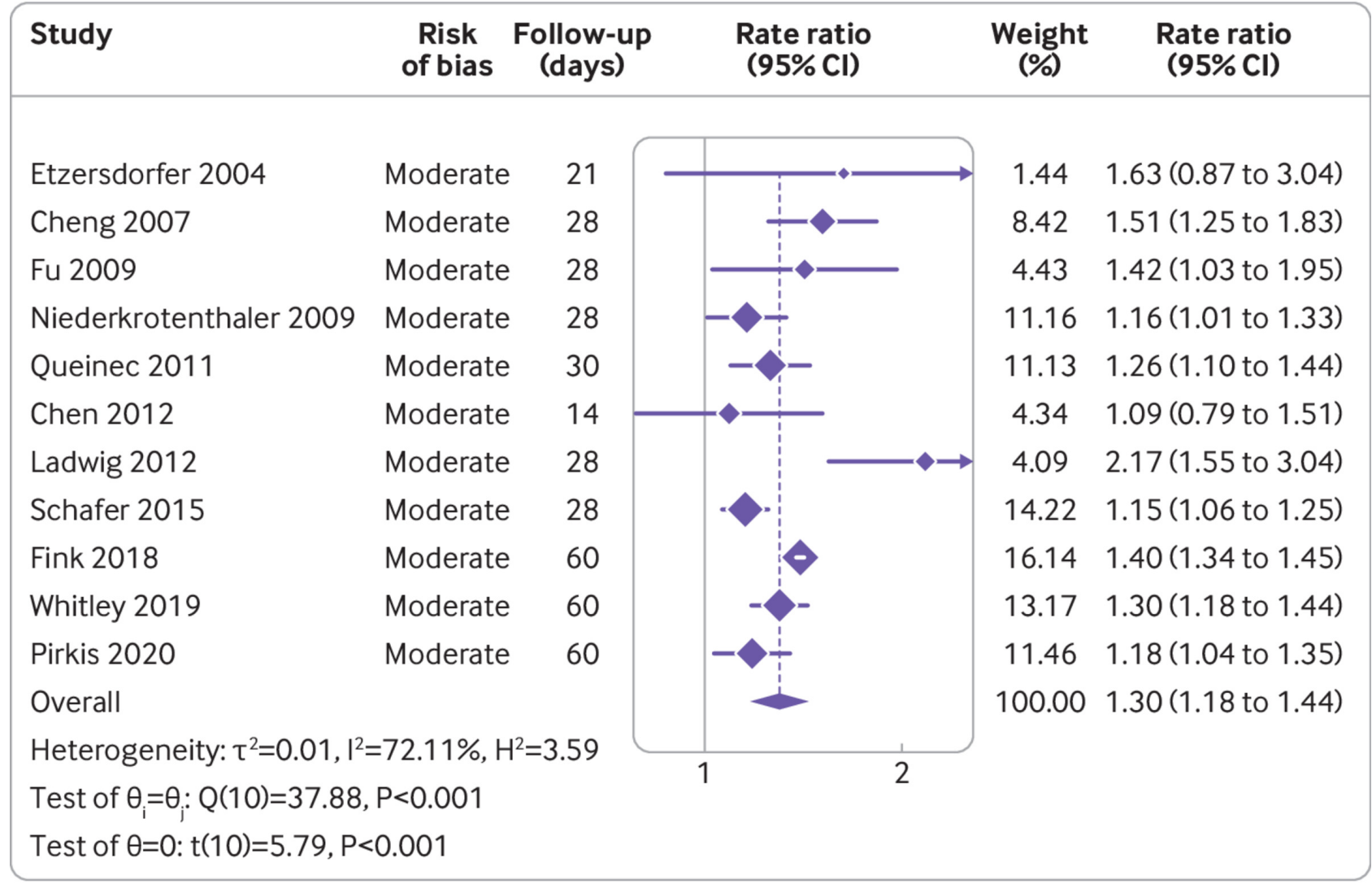

Random effects REML model

Knapp-Hartung standard errors

Fig 3 Forest plot for secondary analysis A: reporting of method of suicide used by a celebrity

\begin{tabular}{|c|c|c|c|c|c|}
\hline Study & $\begin{array}{c}\text { Risk } \\
\text { of bias }\end{array}$ & $\begin{array}{l}\text { Follow-up } \\
\text { (days) }\end{array}$ & $\begin{array}{c}\text { Rate ratio } \\
(95 \% \mathrm{Cl})\end{array}$ & $\begin{array}{l}\text { Weight } \\
\text { (\%) }\end{array}$ & $\begin{array}{c}\text { Rate ratio } \\
(95 \% \mathrm{Cl})\end{array}$ \\
\hline Kessler 1989 & Moderate & 8 & & \multicolumn{2}{|c|}{$13.251 .010(1.000$ to 1.020$)$} \\
\hline Chen 2011 & Moderate & 1 & & 12.17 & 1.007 (0.997 to 1.018$)$ \\
\hline Chen 2013 & Moderate & 1 & & \multirow{2}{*}{$\begin{array}{l}21.66 \\
38.83\end{array}$} & 1.001 (0.993 to 1.009$)$ \\
\hline Chang 2015 & Moderate & 7 & & & $1.000(0.994$ to 1.006$)$ \\
\hline Cheng 2017 & Moderate & 1 & & \multirow{2}{*}{$\begin{array}{c}14.08 \\
100.00\end{array}$} & 1.001 (0.991 to 1.011$)$ \\
\hline Overall & & & & & 1.002 (0.997 to 1.008$)$ \\
\hline $\begin{array}{l}\text { Heterogeneity } \\
\text { Test of } \theta_{i}=\theta_{i}: \\
\text { Test of } \theta=0: t\end{array}$ & $\begin{array}{l}=0.02 \%, \mathrm{H}^{2}= \\
=0.40 \\
.25\end{array}$ & $=1.000 .99$ & 0.991 .00 & \multicolumn{2}{|c|}{1.02} \\
\hline
\end{tabular}

Random effects REML model

Knapp-Hartung standard errors

Fig 4 Forest plot for secondary analysis B: general reporting of suicide 

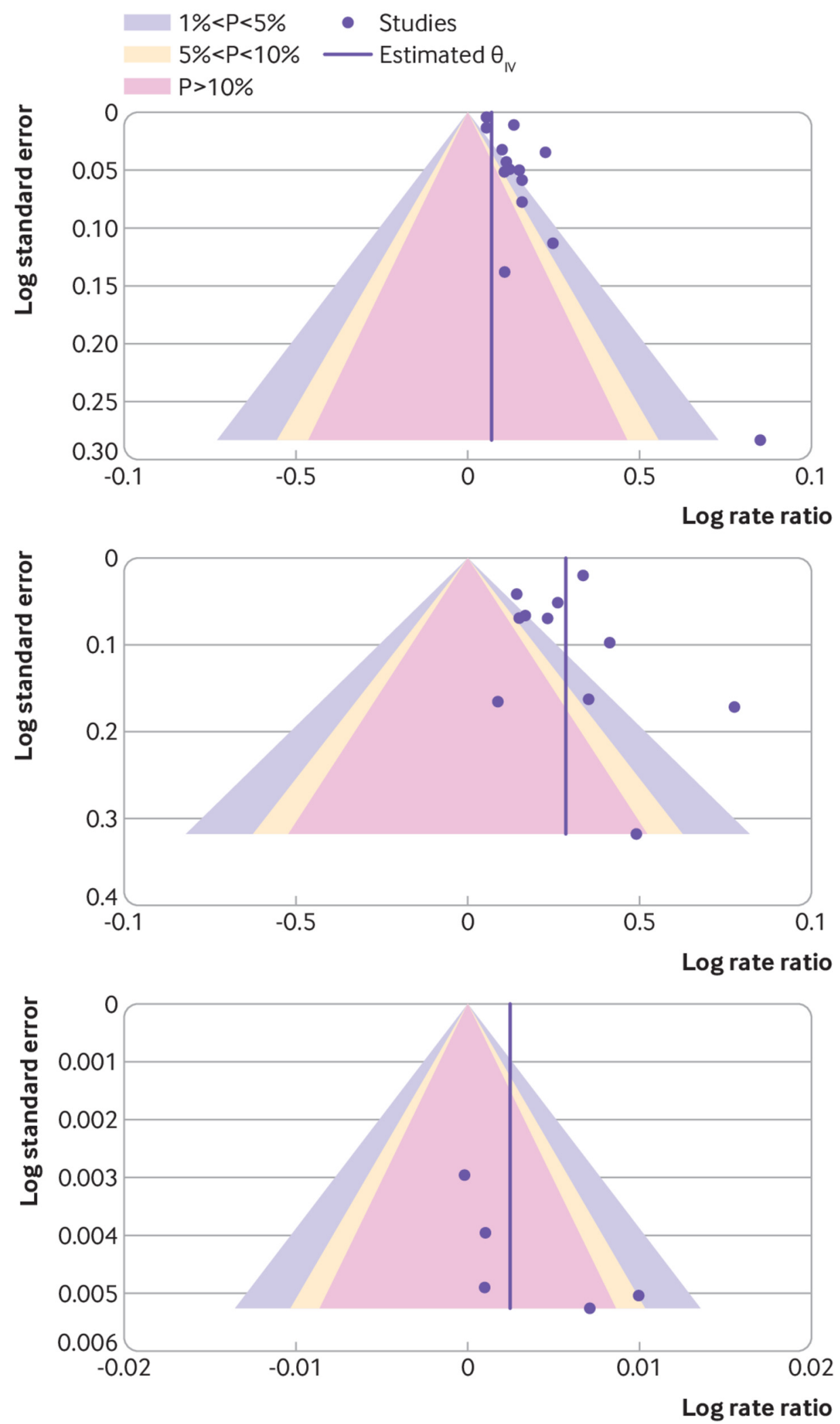

Fig 5 Funnel plots for primary and secondary analyses. Top panel=primary analysis: media reporting of deaths of celebrities by suicide. Middle panel=secondary analysis $A$ : reporting of suicide method used by a celebrity. Bottom panel=secondary analysis $\mathrm{B}$ : general reporting of suicide 